\title{
Participatory Assessment and the Construction of Professional Identity in Folk and Popular Music Programs in Finnish and Australian Music Universities
}

\begin{abstract}
Assessment in music is of considerable importance in the context of higher music education, with major projects focusing on assessment principles and practices in a number of locations, including the European community and Australia. This instrumental case study explores assessment practices in two higher music education contexts, namely within folk music education in Finland and popular music education in Australia. While each of these two instances have significant individual characteristics, they share a focus on understanding assessment as learning and the development of a professional identity through the active participation of the student community in the assessment processes. Drawing on current theories of communities of practice, the narratives of the leaders describing the practices in each context are analyzed to draw attention to the intended learning value derived through the participatory assessment practices.
\end{abstract}

Keywords: assessment, folk music, popular music, professional identity, higher music education

Assessment in higher music education has traditionally been connected mainly to events taking place at the end of a semester or course when it is time to evaluate to what extent the students have achieved the predefined goals of their studies. Assessment scholarship has for some time suggested, however, that rather than being external to the processes of teaching and learning, assessment may in fact steer these processes more than explicit curriculum goals or other pedagogical processes. According to eminent assessment scholars such as Royce Sadler, David Boud and John Biggs, there can be various functions of assessment that are typically characterized as assessment of learning, assessment for learning, and assessment as learning. Assessment of learning refers to the measurement of the degree to which students demonstrate their achievement of the intended learning outcomes of a course of study as demonstrated by their performance in assessment tasks; assessment for learning refers to activities that are primarily intended to provide feedback (or feedforward as it is sometimes called) which then directs the students' future learning activities, while the role of assessment as learning is intended to produce learning in itself and often involves students in the act of assessment as active participants (Lebler, 2008). Importantly, assessment practices can be used to shape not just what students learn, but how they go about that learning (Biggs, 1987; Prosser \& Trigwell, 1999). As Boud says, '[s]tudents can, with difficulty, escape from the effects of poor teaching, [but] they cannot (by definition if they want to graduate) escape the effects of poor assessment' (1995, p. 35). 
Assessment therefore plays an important role in shaping students' learning in higher music education, and may indeed play an even more important role in their studies than teaching (Gibson \& Simpson, 2004). Scholars (Biggs 1999; Prosser \& Trigwell 1999) have argued that students will modify their learning behaviors according to what they think the teacher will assess and learn in ways that will produce the best results for the type of assessment being used. Furthermore, coaching a student through short-term objectives and atomized assessment does nothing to ensure 'the production of truly integrated knowledge and skill' (Sadler, 2007, p. 392). Rather, as Sadler writes, learning oriented assessment 'recognizes fully the responsibility of the teacher to bring students into a deep knowledge of how criteria actually function in making a complex appraisal, and of the need for the assessor to supply adequate grounds for the judgment' (Sadler, 2009, p. 56). It can be argued that inducting students into ways of making multi-criterion judgments holistically brings them into the fold of a guild of professionals who are capable of making valid and reliable appraisals. In other words, students should have the opportunity to engage in the evaluation of their own work and the work of others. In higher education research, students' abilities to think independently and make well-founded judgments have long been regarded as desirable outcomes for higher education. For example, Percy and Salter (1976) found that academics in the UK associated excellence in teaching with the degree to which independence was developed in students; as long ago as the 1980s the Australian Government Department of Employment, Education and Training published a discussion paper (1987) asserting that the primary function of education was to increase individuals' capacities to learn.

This discourse in assessments studies has not yet had a strong impact on higher music education institutions where the established practices arise from the traditional 'conservatory model' of assessing with teacher panels. Typically in this tradition, assessment reflects professional power relations in which the master represents the highest level of knowledge and therefore is the legitimate assessor. Moreover, traditional assessment is more or less the assessing of learning, rather than assessment for or as learning.

In this study, we will explore assessment practices in two higher music education programs, the folk music program at the Sibelius Academy at the University of the Arts Helsinki in Finland and the popular music program at the Queensland Conservatorium of Music at Griffith University in Australia. These programs have been developed within a traditional conservatory context, more or less at the same time, but are about as geographically remote as they could be from each other. In both cases, the current assessment practices differ radically from typical conservatory assessment practices. Both programs include students in the provision of constructive feedback and, in the popular music instance, the awarding of marks. In both contexts, students participate in formal processes of assessment through the use of recorded folios, musical performances, self-assessment, peer assessment and discussions. Importantly, both assessment practices are primarily concerned with the development of the professional identity of the students beyond their degree. Despite obvious artistic differences and distinct contrasts in the processes employed within the two programs and their respective national requirements, both intend to develop student agency and professional identity through practices in which assessment is 
understood as part of learning. Because students actively participate in the assessment process, we will refer to these practices as examples of participatory assessment.

We will examine how the participatory assessment practices in these two higher music education contexts have been developed and the values the practices are based on, as well as the ways these practices and values are connected to the development of students' professional identity. By professional identity, we refer to the negotiated experience as professionals (see Wenger, 1998) and sets of beliefs, attitudes and understandings about their roles, within the context of (music-related) work that students develop through several stages of transition from a student to a professional (e.g. Creech et al., 2008). Through this analysis we aim to engage in a wider discussion on the ways in which the assessment practices in higher music education can be developed by better supporting the growth of students' agency.

\section{Implementation of the study}

The two cases of this study were selected purposefully with the criteria of representing higher music education contexts that are intended to develop students' independence and capacities to learn. The Sibelius Academy folk music program, initiated in 1983, is currently offering education to 27 bachelor and 58 master's level students as well as 18 at doctoral level, and differs in many respect from other European higher folk music education contexts in its strong emphasis on artistic freedom and creativity, improvisation and the creation of a folk music avant-garde (Hill, 2009). As pointed out by Juniper Hill (ibid.), this Finnish folk music program also explicitly

rebels against the nineteenth-century ideology of the Romantic Nationalist Movement, which aimed to bolster Finnish national identity with new artistic expressions drawing on historical Finnish source material, and the Public Enlightenment Movement, which sought to civilise and moralise the Finnish peasants with supposedly cleansed and beautified folk music. (Hill, 2009, p. 209)

Instead, this program has aimed to revive and raise the status of contemporary folk music in the country by assuming that its students have the courage to create and express their own personal music in addition to mastering the traditions.

The popular music program at the Queensland Conservatorium was initiated in 1999 and differs from most conservatory music programs in that it does not include individual instrumental or vocal tuition. Learning through recording is facilitated by the provision of extensive recording facilities and instruction in their operation. Students are encouraged to collaborate, to be responsible for not just the performance, but also the composition and recording of their submissions. While most courses are assessed in traditional ways, mainly by teachers, the creative components of the major study courses are assessed by panels of seven or eight students and a teacher, all of whom have an equal voice in the assessment process. The program offers bachelor level studies for 150 students. (For more details on the structure of this assessment process, see Lebler, 2007, 2008, and 2012.) 


\section{Theoretical points of departure}

In this study, assessment practices are understood to construct a culture of learning and teaching. Furthermore, it is assumed that there is an intertwined relationship between the culture of learning (see, Bruner, 1996) and the construction of professional identity in higher music education institutions. Moreover, rather than an individual cognitive process acquired as the result of teaching in a classroom or other situation set apart from the rest of one's activities, learning is here understood as a social endeavor. Learning can be seen as a social journey (Trayner, 2011) during which learners construct their practices, meanings and identities with respect to the social context.

In conceptualizing the practices of the two specific programs, we employ Etienne Wenger's (1998) concept of a community of practice, a community that is built on the mutual engagement of the participants, who pursue the joint enterprise through ongoing interaction and by developing a shared repertoire including routines, tools and ways of doing things. Within a community of practice learning is seen as participation in the sense of participation as a 'process of being active participants in the practices of social communities and constructing identities in relation to these communities' (p. 4). We employ Wenger's concept of a community of practice heuristically, to refer to such communities where the learning element is fundamental. (For other recent studies in higher music education employing the concept of community of practice, see, for instance, Salavuo, 2008; Rikandi, Karlsen \& Westerlund, 2010; Rikandi, 2013; Westerlund, 2013.) These communities of practice, or learning communities, could be viewed as sustained learning partnerships (Wenger et al., 2011; see also Westerlund \& Karlsen, 2013) between people who are willing to utilize each other's knowledge, skills and experience as their learning resource, and learn together about a specific field of interest. It is not uncommon that the knowledge people have is tacit and is made explicit in a community of practice, thus becoming part of the collective competence and shared expertise of the community - whether or not that would be recognized as expertise outside of the community.

In learning communities, such as our two higher music education cases, learning partnerships extend beyond teacher-student relationships. According to Wenger and his colleagues (2011), in order for the members of such a community to learn together, they must have a shared commitment over a joint enterprise, in other words, a collective intention to advance learning in their domain. We refer to this as the learning value. As Wenger and his colleagues point out, communities of practice are involved in value creation through various social learning activities, such as through the members 'learning from each other's experience, helping each other with challenges, creating knowledge together' and so on (p. 7).

The study is based on a viewpoint according to which individuals and groups of people attempt to make sense of, interpret and give meanings to events around them through narratives (e.g. Bruner, 1990). Over time, a community generates stories about the history, activities and intentions of the community (Wenger et al., 2011). These stories consist of both collective narratives and personal narratives of individual participation that become part of the stories of the community. While the stories individual participants tell are personal in one sense, they do 
not exist in a vacuum but are constructed through interaction over a prolonged period of time with the surrounding cultural conventions of the specific higher music education contexts. In this sense, narratives in this study are considered to be combinations of an individual's own voice and the voices drawn from the surrounding sociocultural world, thus manifesting a cultural membership both by means of the ways people create the stories as well as the content of their stories (Webster \& Mertova, 2007). It is in this sense that we consider narratives not only as a synonym for a story or an account, but as referring to the continuum of narrative as a 'mode of knowing' with its connections to meaning making to a 'method of inquiry' (Barrett \& Stauffer 2009, p. 10). Narratives are thus not understood to be 'self-justifying and self-explicating' (ibid., p. xxxiii); rather, they are viewed as making available a means to construct realities and experiences. This view follows Polkinghorne's (1995, p. 5) description on narrative as 'the type of discourse composition that draws together diverse events, happenings, and actions...into thematically unified goal-directed processes'. Using the terminology provided by the social theory of learning as utilized in this study, narratives can be understood as reifications, hence referring to both a product and a process (see, Wenger, 1998; Wenger et al., 2011). It is through this mutually constitutive process of personal and collective narratives that communities develop a collective identity and frame value creation. According to Wenger and his colleagues (2011), the creation of a collective narrative around a practice can be considered to be an inherent part of the very formation of the community - even when the narrative is contested. Consequently, the stories of how the community started, what has happened so far, and what participants are aiming to achieve, provide a context for understanding what learning is or is not taking place and what value is or is not created within the community.

\section{Data collection and analysis}

The data of this qualitative instrumental case study (Stake, 1995) consist of interviews with three leaders of the folk music program at the Sibelius Academy and two leaders of the popular music program at the Queensland Conservatorium, obtained by means of semi-structured interview procedures (Kvale \& Brinkmann, 2009). As the study aimed to examine the development of assessment practices in these two higher music education contexts, the criterion for selecting the participants was to interview the program leaders who have been involved in the program either since the beginning or at least during the years when changes in the assessment practices were implemented. Typically for an educational study that aims to focus on the participants' 'experience of a theme' (ibid., p. 25), the interviews aimed to 'obtain descriptions of the interviewees' lived world with respect to interpretation of the meaning of the described phenomena' (p. 27). The individual interviews ' were conducted according to an interview guide that focused on the assessment principles and practices developed and used in the respective programs over time. The interviews were transcribed word-by-word, and the transcriptions and sound recordings together were considered to constitute the study's research data.

The interviews with the leaders were treated as 'narratives', 'accounts' and as 'performances' (see, for instance, Atkinson \& Coffey, 2002; Barrett \& Stauffer, 2009), in which the interviewees were justifying particular actions and retrospectively constructing specific recounted events 
(Atkinson \& Delamont 2006, p. xxxv). Through the theoretical lense of value creation, as described above, we understand that the accounts of the program leaders reflect the mutually constitutive process of personal and collective narratives of the respective learning communities. The aim of the analysis was to examine the ground narratives and aspirational narratives of both learning communities to explore how the leaders of the folk music and popular music programs narrate 1) the development of the assessment practice, or rather, assessment as learning in their community, and 2) the aims and criteria for success in that practice. Following Wenger's terminology, by ground narrative we refer to 'accounts of what has happened and is happening in the everyday life of a community' as well as to 'the formative events' that have shaped the development of it, to 'the activities that members engage in, the interactions and experiences they have, and the roles people play' (Wenger et al., 2011, p. 16). Aspirational narratives are stories about what the members of a community think that the community should be: accounts of 'what a person is trying to achieve' and 'what defines success for a community' (pp. 16-17). The accounts of the leaders in the two programs reflect their personal aspirational narratives intertwined with those of the respective community. By following Wenger and colleagues, we view the tension between the ground narratives and aspirational narratives as creating a space for deciding 'what is worth learning' (p. 17), in other words, for the evaluation of the learning value of the music programs' changed assessment practices.

After several readings of the word-by-word transcriptions of all the interviews, the analysis proceeded by identifying the patterns drawn from the research task and the abovementioned theoretical postulations (see Stake, 1995; Schwandt, 2001). An increasing familiarity with the data prompted a revision of the initial thematization, and some initial categories were merged into three main themes, namely 'Counter-narratives within conservatory contexts', 'Ground narratives of the two programs', and 'Aspirational narratives articulating educational values'. The outcome of this analysis is presented as a thematized depiction of the participatory assessment practices in the next sections of this article. As this research seeks to explain - rather than merely describe - the assessment practices, the analysis aimed to draw together different perspectives provided by the leaders' interviews in both contexts, and to cross-examine those perspectives by developing a theoretical synthesis that could act as an analytical tool used to draw theoretical conclusions beyond the cases and with respect to the overall research task (see, for instance, Eisenhardt, 2002; Wells, Hirshberg, Lipton \& Oakes, 2002; Stake, 2006). The aim was also to suggest implications for the wider field of higher music education arising from this dual case study.

\section{Counter-narratives within conservatory contexts}

As with many stories, the accounts of the music program leaders at the Sibelius Academy and the Queensland Conservatorium were 'born in trouble', to use Bruner's (1985, p. 142) expression. The accounts of the leaders of our two case study sites show that the changes made with regards to assessment practices were based on a discontentment with the ability of traditional conservatory assessment practices, developed within very different kinds of artistic practices, to facilitate learning. 
Leaders from the Sibelius Academy's folk music program tell that

We were a little bit unhappy about the result or the practice in what happens during the assessment of the personal performance examinations especially. Because they are the most vulnerable, they are the core of the students' work. [...] We were not happy because we had more or less been a follow in the conservatory tradition (Leader 2, Folk music program)

We began to feel that assessing and grading an artistic performance and even giving feedback after the exam is a bit late, in a sense [...] I was increasingly critical toward that feedback as it felt so futile [...] members of the jury arrive in an exam to listen to something they have never heard before, and then they quickly express their opinion. Considering that the student has worked for it for a year or two that felt somehow grotesque! (Leader 3, Folk music program)

The interviews from the Sibelius Academy also show that by the end of the 1990's, the leaders of the folk music program felt that there was a risk of the whole concept of Finnish folk music becoming increasingly narrow and the role of improvisation almost vanishing from the music practices.

There was a sense that the system is pushing [the program] towards a certain [rigid] direction...So we transformed the entire curriculum in a very radical way concerning all aspects of it, and aimed to make sure that it would be as versatile as possible. At the same time, we put this concept of improvisation on the table [...] all the students were required to do the older, middle-age and recent tradition as well as their own compositions and impro. (Leader 3, Folk music program)

By changing the teaching as well as the assessment practices, the goal of the folk music program leaders was to revive the ideal of versatility in Finnish folk music and to ensure the students would not only learn the tradition but would also be able to reform and progress contemporary folk music by improvising and composing.

At the Queensland Conservatorium the discontentment was related to a belief that popular musicians usually learn with and from each other, and that relinquishing the assessment process to teachers would run counter to this characteristic. A leader from the Queensland Conservatorium explains,

It was tricky [at the beginning of the program] because well, how do you mark popular music product? It's impossible because it doesn't rely on the type of technical, formal rules that we have in classical music. ... What I didn't want to see happen was for lecturers to be pointing the students into a particular music genre... (Leader 1, Popular music program) 
Enhancing students' abilities to provide well-presented constructive feedback was seen as a primary learning objective for the programs (see, e.g., Lebler, 2006a, 2006b; McWilliam, Carey, Draper \& Lebler, 2006). As such, in both contexts it was considered appropriate to question the established assessment practices and initiate new practices in the pursuit of facilitating learning that would strengthen student agency and professional identity construction, also through the assessment practices. Similarly, as these new practices have been developed in relation to the surrounding wider conservatory-based educational culture, the related shared narration on and within the educational community, including the narration about the assessment practice, represent a critical counter-practice (Peters \& Lankshear 1995, p. 2), or counter-narrative (Bamberg \& Andrews, 2004, p. x) in each of their local institutional contexts. Such counternarratives of pedagogy are said to 'draw on progressive aspects of extant narratives and critiques their counterproductive tendencies, in pursuit of narratives of democratic pedagogy in opposition to official normalizing conceptions and practices of 'instruction and measurement' (Peters \& Lankshear 1995, p. 31).

\section{Invitation for the students to participate: ground narratives of the two programs}

In the folk music program of the Sibelius Academy, an important form of assessment takes place as public exams that resemble in many respects authentic concert situations where the audience consists of colleagues, including fellow students and teachers, as well as people outside of the department. Before the exam-concert, the student presents a written statement to the jury. In the statement, she explains her choices of repertoire or her ways of composing her own music, and reflects on her own process of learning in relation to the objectives she has set for herself at the beginning of the semester and in cooperation with her teacher. After the public exam-concert, the faculty teachers and students participate together in the assessment of the exam-concert. The assessment begins with the student's primary teacher's reflection on the process, which is then followed by the student's self-reflection. During the self-reflection, the student can both re-reflect on the issues stated in the written analysis as well as on her performance in the exam-concert. Next, the jury - consisting of other teachers in the folk music program - will evaluate the performance. Importantly, as pointed out by the interviewees, instead of stating their opinions and critique, the jury attempts 'to ask as many questions as possible', as one of the leaders explains.

...because our students very much make their own music... often the discussion is about how the music became like this and what was the original goal. Why did you choose this kind of combination of ensemble...or these people to accompany you? Or, how did you prepare your instrument because it sounds now very nice or strange or whatever. Or we can talk about - is this folk music? Where is the border and what is really folk music? (Leader 2, Folk music program)

Finally, her colleagues in the audience will have a chance to ask questions or comment upon the performance. The discussion is deliberately focused on professional choices and artistic viewpoints instead of technical details. 
We like to think that in the university level the student already has to possess a lot of technical skills. If there are not technical skills enough then it's the matter of the teacher to teach that and take care that the student doesn't fall to the examination before it's okay in this sense as well. It's too late in the examination concert to notice this little detail. There it should be really art and music and freely flowing interpretation and personal creativity. (Leader 2, Folk music program)

Importantly, each assessment panel has a chair, who is responsible for setting the 'pedagogical tone' of the assessment. The chair ensures that everyone willing to contribute to the assessment will have an opportunity to comment, and that the comments given are constructive and encouraging.

In the popular music program, students submit recordings of their original compositions along with documentation reporting on what they were trying to achieve with the recording, details about who else was involved and what they contributed. Comments on how well the objectives were achieved are also included. Students mark their own submissions with reference to the same criteria and standards that are used in later stages of the assessment process. Students are therefore the first to make formal judgments about their own work. The complete submissions of seven or eight students from all year levels of the program are assigned to panels consisting of one teacher and seven or eight students who conduct the formal assessment of the recorded material. This complex process now occurs using the online Bachelor of Popular Music Assessment Tool (BoPMAT). Students are expected to engage in the process as assessors in the panel by listening to the recorded material in advance and reading the associated track reports. Submissions are made available on line via BoPMAT before the panels meet to refine their assessments by listening to the submissions in reference standard listening environments in the recording studios of the conservatory's popular music program. Each panel member provides anonymous written feedback and gives marks for every track assigned to their panel. A marking guide is provided along with guidelines for the written feedback. Importantly, playlists of the work of previous students are available on line, arranged 'top 40' style, on the basis of each track's 'how good is this track overall' mark. (For more details of this assessment practice, see Lebler, 2007, 2008 and 2012.)

Although peer assessment has traditionally been thought of as adding to the workload of both students and teachers, and may be considered as undermining the authority of lecturers, Sadler (1989) believes that authentic evaluative experiences provide for the development of evaluative expertise and intelligent self-monitoring in students. Students thus learn from the experience of assessing their peers (Biggs, 1999). Moreover, the inclusion of students into assessment practices diminishes the possibility of assessment becoming a means teachers utilize to exercise power over their students. Such an exercise of power was also criticized explicitly by the folk music leaders: 
... within classical music studies the grading is teachers' means for using power, period. It has no other meaning. [...] The teachers wanted to rank their students [...] so that they [the students] would understand how good they are (Leader 3, Folk music program)

\section{Assessment and intended learning outcomes: aspirational narratives articulating educational values}

While the ground narratives provide illustrations of the formative events in both music programs, the aspirational narratives reveal, among other things, the intended learning outcomes of the assessment practices. The aspirational narratives of the program leaders in both contexts show that the changes implemented in assessment practices intended to shift the emphasis away from the traditional function of assessment used solely to measure students' understanding of curriculum content (assessment of learning) towards using assessment for and as learning. All the interviewed leaders stressed the importance of equipping students with the tools needed to grow into independent professionals, capable of assessing their own work, and reflecting on it in relation to the work of others and the boundaries of specific musical styles and genres. By emphasizing students' own active role in the assessment process, both programs aim to strengthen students' identity as professional musicians rather than as pupils reliant on the teacher's opinion.

The leaders from the folk music program state:

-- we felt we have to emphasize...how to empower the student to become independent and self-evaluating and self-active individuals so that they can cope whatever comes in their way when they graduate. (Leader 2, Folk music program)

[The students] need to learn to trust what they are doing and it doesn't come in that way that somebody comes and tells if you are good or bad in something --[They need] to act like grownups....understand from the very beginning...I'm responsible in my studies and I have to be able to learn to analyze what I am doing and why and where is my direction and what is going on. (Leader 1, Folk music program)

The role of peer-assessment and collaboration is considered crucial in both contexts. By emphasizing the importance of attending to the assessment of their peers, the students are encouraged to learn not only how to receive feedback positively, but also how to express their views in a constructive and professional manner. One of the apparent intentions in the folk music program is to encourage students to view themselves as part of a wider community of folk musicians by, for instance, emphasizing that one of the purposes of exam-concerts is to provide a forum for the students to display their music and skills to their future colleagues. 
...[students] understand that this [the exam-concert] is their place where their future work is depending ... the colleagues are there and the future co-workers are there. (Leader 1, Folk music program)

It is acknowledged that strengthening the students' professional identity throughout their studies is essential in preparing them to take their place in an ill-defined professional field where one has to 'focus on finding [one's] own way' (Leader 1, Folk music program), and to create one's own career as a freelance musician. As one of the folk music leaders expressed:

It's very important that each student that we educate becomes a strong individual because they have to cope in a strong world. They have to fight for themselves. They don't have positions in orchestras waiting for them to go and compete of they don't have positions in music education, they don't have positions in music schools where you could go and apply. They have to make the profession themselves so it's a very hard world for them out there. (Leader 2, Folk music program)

While graduates from the folk music program enter a professional field with no clear career paths, popular musicians will face different kind of demands. Although they, too, are likely to be required to create their own careers, often as freelancers, the popular music industry sets requirements that differ from any other genre. Hence, in the popular music program, equipping the students to take their place as independent actors in the music business is regarded as one of the main goals.

[The assessment process] introduces them [the students] to the music industry. Their product is going to be reviewed and criticized and applauded so it gets them used to taking often productive criticism so they would have a heightened level of industry engagement... when they go into the workforce. (Leader 1, Popular music program)

... the ability to provide constructive criticism, to give feedback, to collaborate, to respect the opinions of your peers...these are all things that are valued by employers... (Leader 2, Popular music program)

The leaders in the popular music program also emphasize that popular musicians are expected to have a very wide understanding of different musical styles and subgenres, and to be flexible enough to work within a variety of contexts as performing artists, studio producers and songwriters for themselves or other musicians, and also for films and advertising.

..I see the students needing to engage with a whole range of media; not only the three-and-a-half minute pop song... (Leader 1, Popular music program)

Importantly, it is not enough for professional pop musicians to be masters solely in their own styles or instruments; an aspiring pop musician is expected to have a 'stock of knowledge to 
better judge the music' (Leader 1, Popular music program) across a variety of popular music styles. According to one of the leaders in the popular music program,

... pop music relies on collaboration, students need to get together in small groups, collaborate, find their likes and dislikes regarding music styles and then draw upon other students' stock of knowledge that they mightn't even be aware of without these peer assessment panels. (Leader 1, Popular music program)

Welcoming students from different year levels to assess each others' music is acknowledged as an important way of providing the students with opportunities to create learning partnerships with each other and to use each other's expertise as their own learning resource in familiarizing themselves with different styles.

...it's important for them to engage with other students and be part of the peer assessment panel because they talk about the musical style... it's a learning experience for them. If one first year student comes across a style that they have never encountered before...then in our discussions the third and second years would actually explain: "Oh, you know, we're listening to this or this is appropriate for this style or it needs to be recorded to sound like that." So it's a really important learning environment. (Leader 1, Popular music program)

It is acknowledged both at the Sibelius Academy and the Queensland Conservatorium, that providing authentic and guided evaluative experiences is essential for students to become insiders in the assessment process, active participants and agents, rather than limiting them to the role of passive consumers of assessment completed by the teachers. The development of expertise in evaluative techniques by students is an important objective of assessment, because it assists them in working towards an understanding of quality and applying this in their professional lives. By inviting the community of fellow students into the assessment process, the aim is to also develop a shared understanding of quality and a shared professional knowledge in addition to developing effective communication skills (Lebler, 2013).

\section{Participatory assessment within diverse institutional frames and differing ideologies}

Narratives are never simply statements of facts, but always reveal something about the values of any given community (Porter \& Kelso, 2010). The collective narratives of the folk music and popular music programs reveal a strong emphasis on skills, competences and attitudes that are required in employment market. Students are assumed to be acting as professional artists from the beginning; to be able to show independence and versatility as well as to be able to collaborate. Naturally, the goals and institutional frames of the two programs also differ from each other, as do the style-related ideologies and professional requirements. Whereas Finnish folk musicians locate themselves at the margin of music culture - albeit many of them have created international careers (Hill, 2009) - the popular music program refers to the vast market and commercial demands even beyond the borders of Australia. Naturally, the assessment 
practices are aligned with the professional context and goals of each program, thus reflecting the different areas of emphasis in each.

Despite these differing frames of reference and cultural conditions for constructing their professional identities, the understanding of what is worth learning in a university so as to grow professionally are very similar. In both the folk music and popular music programs, the collective narratives create a continuum from assessment to learning and professional artistic work. According to Hill (2009), the agenda of the folk music program at the Sibelius Academy has been to 'rescue creativity' - an agenda that has shaped the curriculum and teaching methods over the years (p. 222). This includes the thought that graded assessments completed by a teacher panel was considered to violate students' artistic growth. A general freedom in developing educational practices at the Sibelius Academy has allowed the folk music program to give up numeral grading at the same time as most other students in the university still receive it (numeral grading is not obligatory within the Finnish higher music education system).

As with all programs of study at Griffith University, the popular music assessment process is governed by the University's institutional assessment policy that demands numeral marking. The development of the Griffith's current assessment policy has been strongly influenced by the work of Royce Sadler. Sadler (2011) identifies the tension between academics' belief in their right and ability to grade their students' work autonomously, and the responsibility of institutions to monitor and regulate standards. He stresses the importance of aiming for integrity in grading through achieving 'grades, degrees and qualifications that are comparable not only across institutions but also across provincial and national boundaries' (Sadler, 2011, p. 86). In achieving integrity, Sadler insists that grades must represent 'the quality, breadth and depth of the level of achievement a student reaches' (p. 88) and must not include other considerations unrelated to achievement. Sadler calls for academics to move from assessing in isolation as autonomous experts to working as part of a 'body of educator-professionals that is collectively responsible for contributing to students' learning' (p. 96). He promotes the use of consensus moderation in order to increase consistency in the grading process and to reach agreement on marking standards (Sadler, 2011).

The assessment panel method developed in the Australian popular music program exemplifies consensus moderation, since after a period of preparation, the members of the panel meet to finalize their assessment duties. Panel members are encouraged to talk about their impressions of the work under consideration and this effectively develops consensus among panel members as to the quality of the submissions they are assessing. The availability of all the assessment submissions in the BoPMAT ensures consistency between assessment panels, and the availability of cumulative 'Hot 100' playlists ensures consistency over time. In addition, very explicit criteria statements as to appropriate marks for particular standards of work are available to panel members. The primary purpose for criteria-based assessment and grading is to communicate to students in advance how judgments of the quality of their performances will be made, answering Sadler's call for a major shift towards standards-referenced grading because 'ultimately it is the students' appreciation of quality, set against a background of external standards that is of significance' (Sadler, 2005, p. 190). 
Despite their differences the two programs embody the general potential of a learning community in their assessment practices. In both instances, participatory assessment is applied to individual students, but all the teachers and students are mobilized around joint tasks and negotiations of meaning. In these programs, this negotiation continues over multiple years in a variety of settings so that during these tasks and negotiations the members of the community of practice become aware of who they are, what they can do, who knows what, and how they can utilize collaboration without compromising their individual professional identities. In other words, professional identity is not a title or a degree as such, but it is constructed and created in and through various institutional negations.

The leaders both in the folk music program at the Sibelius Academy and the popular music program at Queensland Conservatorium have been and are deliberately aiming to construct such a culture within which the students learn together and create expertise in collaboration. One could ask whether a culture within which the students are not directed to understand each other as colleagues and cooperation partners, but rather to view each other merely as competitors and threats to their own success, is weakening or strengthening the profession. Naturally, participatory assessment practices will play out differently in any given context. The case studies presented here will hardly offer any universal models of assessment practices that could or even should be directly applied to other institutional contexts. Rather, they illustrate the importance of any given educational community determining how assessment might look within that very context to best serve the purpose of supporting the development of student agency and professional identity. Looking from the critical pedagogy point of view, the two assessment practices can also be seen as ways towards a more transformative pedagogy in higher music education that actively - and even against hegemonic institutional norms - seeks practices, 'which enact democratic uses of knowledge, texts and cultural productions' (Peters \& Lankshear 1996, p. 31).

\section{Conclusion}

Studies on assessment agree unanimously that it is vital that assessment activities align with the learning outcomes intended for the activity being assessed. Moreover, it is essential that the cumulative effect of the assessment experienced across all their studies enhance those attributes we seek to develop in our students. Changes in assessment practices in higher music education may take time. However, the two cases in Finland and Australia encourage teachers in higher music education to reflect on assessment practices in relation to the aspired educational values and goals, and to implement changes even when changing deeply rooted practices may initially meet with resistance. The cases exemplify that radical changes are possible within a reasonable time span through explicit rules and constant collective reflection. When considering that the narratives about the changes are not simply about facts but also about values, there may be a wider need to reconsider how the values of higher music education have changed in recent decades, and thus a need to change and readjust the community story, or to create new counter-narratives and counter-practices, especially related to assessment and even within older, already steadily established programs within higher music 
education; in other words to get everyone on board and make everyone understand why the changes are done. These systematic changes are also likely to have a significant impact on the whole educational culture in these programs, hence increasing student agency, strengthening professional identity formation and a sense of professional community not just within the program, but even beyond.

\section{References}

Atkinson, P.A., \& Coffey, A. (2002). Revisiting the relationship between participant observation and interviewing. In J.F. Gubrium \& J.A. Holstein (Eds.), Handbook of interview research (pp. 801-814). Thousand Oaks, CA: Sage.

Atkinson, P., \& Delamont, S. (2006). Editor's introduction: Narratives, lives, performances. In P. Atkinson \& S. Delamont (Eds.), Narrative methods. Volume I: Narrative perspectives (pp. xixliii). London, UK: Sage.

Bamberg, M., \& Andrews, M. 2004. Introduction to the book. In M. Bamberg \& M. Andrews (Eds.), Considering counter-narratives. Narrating, resisting, making sense (pp. ix-x). Amsterdam \& Philadelphia: John Benjamins Publishing.

Barrett, M.S., \& Stauffer, S.L. (2009). Narrative inquiry: From story to method. In M.S. Barrett \& S.L. Stauffer (Eds.), Narrative inquiry in music education: Troubling certainty (pp. 7-18). London, UK: Springer.

Biggs, J. B. (1987). Student approaches to learning and studying. Retrieved from http://eric.ed.gov/PDFS/ED308201.pdf

Biggs, J. B. (1999). Teaching for quality learning at university: what the student does. Philadelphia \& Buckingham, UK: Society for Research into Higher Education; Open University Press.

Boud, D. (1995). Assessment and learning: contradictory or complementary? In P. Knight (Ed.), Assessment for learning in higher education (pp. 35-48). London, UK: Kogan Page.

Bruner, J. (1990). Acts of meaning. Cambridge: Harvard University Press.

Creech, A., Papageorgi, I., Duffy, C., Morton, F., Haddon, E., Potter, J., . . . Welch, G. (2008). From music student to professional: The process of transition. British Journal of Music Education, 25(3), 315-331.

Department of Employment, Education and Training (1987). Policy discussion paper on higher education. Canberra: Australian Government Printing Service. 
Eisenhardt, K.M. (2002). Building theories from case study research. In A.M. Huberman \& M.B. Miles (Eds.), The qualitative researcher's companion (pp. 5-36). Thousand Oaks, CA: Sage.

Gibson, G., \& Simpson, C. (2004). Conditions under which assessment supports students' learning. Learning and Teaching in Higher Education, 1, 3-31.

Hill, J. 2009. The influence of conservatory folk music programmes: The Sibelius Academy in comparative context. Ethnomusicology Forum, 18(2), 207-241.

Kvale, S., \& Brinkmann, S. (2009). InterViews: Learning the craft of qualitative research interviewing. Thousand Oaks, CA: Sage.

Lebler, D. (2006a, 10-14 July, proceedings published 2007). 3D assessment: looking through a learning lens. Paper presented at the New models for educating professional musicians in the twenty-first century: proceedings of the 16th International Seminar of the Commission for the Education of the Professional Musician (CEPROM), Hanoi National Conservatory of Music, Hanoi, Vietnam.

Lebler, D. (2006b). The masterless studio: an autonomous education community. Journal of Learning Design, 1(3), 41-50.

Lebler, D. (2007). Student-as-master? Reflections on a learning innovation in popular music pedagogy. International Journal of Music Education, 25(3), 205-221. doi: DOI: 10.1177/0255761407083575

Lebler, D. (2008). Popular music pedagogy: peer-learning in practice. Music Education Research, 10(2), 193-213. doi: 10.1080/14613800802079056

Lebler, D. (2012). Technology and students' musicking: Enhancing the learning experience. Theory Into Practice, 51(3), 204-211. doi: 10.1080/00405841.2012.690302

Lebler, D. (2013). Using formal self- and peer-assessment as proactive tools in building collaborative learning environments: theory into practice. In H. Gaunt \& H. Westerlund (Eds.), Collaborative Learning in Higher Music Education: Why, What and How? Farnham, UK: Ashgate.

McWilliam, E., Carey, G., Draper, P., \& Lebler, D. (2006). Learning and unlearning: New challenges for teaching in conservatoires. The Australian Journal of Music Education, 1, 25-31.

Percy, K. A., \& Salter, F. W. (1976). Student and staff perceptions and "the pursuit of excellence" in British higher education. Higher Education, 5, 457-483. 
Peters, M. \& Lankshear, C. 1995. Postmodern counternarratives. In Henry Giroux, Colin Lankshear, Peter McLaren \& Michael Peters (Eds.), Counternarratives. Cultural studies and critical pedagogies in postmodern spaces (pp. 1-39). London: Routledge.

Polkinghorne, D. (1995). Narrative configuration in qualitative analysis. In J. A. Hatch \& R. Wisniewski (Eds.), Life history and narrative (pp. 5-24). London, UK: The Falmer Press.

Porter, M., \& Kelso, J. 2010. Introduction. In Marie Porter \& Julie Kelso (Eds.), Mother-texts. Narratives and counter-narratives (pp. xiii-xxii). Newcastle, UK: Cambridge Scholars Publishing.

Prosser, M., \& Trigwell, K. (1999). Understanding learning and teaching: the experience in higher education. Buckingham, UK: The Society for Research into Higher Education and Open University Press.

Rikandi, I. (2013). Liberation through collaboration: A project of piano Vapaa Säestys group studies in Finnish music teacher education. In Helena Gaunt \& Heidi Westerlund (Eds.), Collaborative learning in higher music education (pp. 187-192). Farnham: Ashgate.

Rikandi, I., Karlsen, S., \& Westerlund, H. (2010). Bridging practices in Nordic music education doctoral programmes: Theorising and evaluating the Finnish application of the Piteå model. In Cecilia Ferm Thorgersen \& Sidsel Karlsen (Eds.), Music, innovation and education: Festschrift for Sture Brändström (pp. 165-190). Luleå: Luleå University of Technology.

Sadler, D. R. (1989). Formative assessment and the design of instructional systems. Instructional Science, 18, 119-144.

Sadler, D. R. (2005). Interpretations of criteria-based assessment and grading in higher education. Assessment and Evaluation in Higher Education, 30(2), 175-194.

Sadler, D. R. (2007). Perils in the meticulous specification of goals and assessment criteria. Assessment in Education: Principles, Policy \& Practice, 14(3), 387-392.

Sadler, D. R. (2009). Transforming holistic assessment and grading into a vehicle for complex learning. In G. Joughin (Ed.), Assessment, learning and judgement in higher education (pp. 4564). London, UK: Springer.

Sadler, D. R. (2011). Academic freedom, achievement standards and professional identity. Quality in higher education, 17(1), 85-100.

Salavuo, M. (2008). Social media as an opportunity for pedagogical change in music education. Journal of Music, Technology \& Eduction, 1(2-3), 121-136.

Schwandt, T. (2001). Dictionary of qualitative inquiry. Thousand Oaks, CA: Sage

Stake, R. (1995). The art of case study research. Thousand Oaks, CA: Sage. 
Stake, R. (2006). Multiple case study analysis. New York, NY: The Guilford Press.

Trayner, B. (2011, April 17). Social learning - on a high horse [Web log post]. Retrieved from http://www.bevtrayner.com/base/

Webster, L., \& Mertova, P. (2007). Using narrative inquiry as a research method. An introduction to using critical event narrative analysis in research on learning and teaching [Kindle version]. London, UK \& New York, NY: Routledge.

Wells, A.S., Hirshberg, D., Lipton, M., \& Oakes, J. (2002). Bounding the case within its context: a constructivist approach to studying detracking reform. In A.M. Huberman \& M.B. Miles (Eds.), The qualitative researcher's companion (pp. 331-348). Thousand Oaks, CA: Sage.

Wenger, E. (1998). Communities of practice. Learning, meaning, and identity. Cambridge, UK: Cambridge University Press.

Wenger, E., Trayner, B., \& de Laat, M. (2011). Promoting and assessing value creation in communities and networks: A conceptual framework. Retrieved from http://bevtrayner. com/base/docs/Wenger_Trayner_DeLaat_Value_creation.pdf

Westerlund, H. (2006). Garage rock bands: a future model for developing musical expertise? International Journal of Music Education, 24(2), 119-125. doi. 10.1177/0255761406065472

Westerlund, H. (2014). Learning on the job: Designing teaching-led research and research-led teaching in a music education doctoral program. In S. Harrison, S. (Ed.), Research and Research Education in Music Performance and Pedagogy (pp. 91-103). Dordrecht: Springer.

Westerlund, H. \& Karlsen, S. (2013). Designing the rhythm for academic community life: Learning partnerships and collaboration in music education doctoral studies. In $\mathrm{H}$. Gaunt \& $\mathrm{H}$. Westerlund (Eds.), Collaborative Learning in Higher Music Education (pp. 87-99). Farnham: Ashgate.

\footnotetext{
' The individual interviews were conducted in English by all three researchers either face-to-face or, due to geographical impediments, via Skype connection, except for one interview which was conducted in Finnish by the two Finnish speaking researchers. Each interview lasted approximately 60 minutes.
} 